\title{
CFD AND CONJUGATE HEAT TRANSFER ANALYSIS OF HEAT SINKS WITH DIFFERENT FIN GEOMETRIES SUBJECTED TO FORCED CONVECTION USED IN ELECTRONICS COOLING
}

\author{
V. M Kulkarni ${ }^{1}$, Basavaraj Dotihal ${ }^{2}$ \\ ${ }^{1}$ Professor, Thermal Power Engineering, VTU RC Gulbarga, karnataka, India \\ ${ }^{2}$ Student, Thermal Power Engineering, VTU RC Gulbarga, karnataka, India
}

\begin{abstract}
Heat sinks are commonly used for cooling of electronic devices. Heat sinks, an array of heat fins, remove the heat from the surfaces of the chips by enhancing the heat Transfer rate through heat conduction process. Heat can also be removed from the chip surfaces through forced convection heat transfer. In this project work, CFD and conjugate heat transfer analysis is carried out for various fin geometries with Zigzag, Fluted, Slanted mirror, Custom pin fin and staggered array configurations for low thermal resistance and minimum pressure drop. Numerical simulations are carried out for each of the above mentioned fin geometries with common base plate thickness of $2 \mathrm{~mm}$, fin height of $28 \mathrm{~mm}$ and fin thickness of $1 \mathrm{~mm}$ for three different heat loads namely $50 \mathrm{~W}, 75 \mathrm{~W}$ and $100 \mathrm{~W}$ with air flow of $3.933 \mathrm{~m} / \mathrm{s}(15 \mathrm{ft} / \mathrm{min}$ or $15 \mathrm{CFM})$ and air inlet temperature of $25^{\circ} \mathrm{C}$. The results are compared for thermal performance of a heat sink for each of above geometries and it is observe that the fin with Slanted Mirror geometry gives the best performance among all the other geometries for minimum Pressure drop. The average heat transfer coefficients for fins with slanted mirror geometry, zig zag configuration, fluted type, custom pin fin and staggered array are found to be $215 \mathrm{~W} / \mathrm{m} 2 \mathrm{~K}, 164 \mathrm{~W} / \mathrm{m} 2 \mathrm{~K}, 164 \mathrm{~W} / \mathrm{m} 2 \mathrm{~K}, 157 \mathrm{~W} / \mathrm{m} 2 \mathrm{~K}$ and $145 \mathrm{~W} / \mathrm{m} 2 \mathrm{~K}$ respectively
\end{abstract}

Keywords: Fin geometries of Heat sinks, Computational Fluid Dynamics, Conjugate heat transfer.

\section{INTRODUCTION}

Nowadays trend in electronics industry to produce small and compact size goods that can be accommodated in given space, which is constraint in many cases. The heat generated due to active components in such electronic devices is enormous, may be the order of $100 \mathrm{~W} / \mathrm{m}^{2}$. It is therefore necessary to remove the heat generated, which otherwise detriment to the life of such devices and their reliability. Heat sinks are used to remove the heat generated in electronic components. Heat sink is nothing but an array of fins or extruded surfaces remove the heat from the localized point through heat conduction and convective heat transfer process. Heat sink is attached to a electronic chip to help prevent the chip from overheating. In order to design a better heat sink, factors are such as higher heat transfer rate, low pressure drop, lowest maximum temperature attained in operation, lower thermal resistance, easy manufacturing process, a simple structure and material with high thermal conductivities are to be considered.

\subsection{Objectives}

The main objective of the work is presented as

1. To investigate the conjugate heat transfer analysis for heat sinks those are being used in electronics cooling. This involves the combined fluid flow analysis by making use of CFD equations and heat transfer analysis, considering separately convection process in fluid flow region and conduction heat transfer in solid region.
2. To carry out heat transfer analysis for different fin configurations considering the conduction heat transfer from base plate to heat fins.

3. To conduct computational fluid flow analysis for different fin configurations, for fluid part, by solving Navier-Stroke equations to get velocity vectors, pressure contours and temperature fields for given inlet air velocity. Standard k- $\varepsilon$ model is adopted to account for turbulence phenomenon. The temperature field is used to get quantity of heat dissipated or carried away by convection.

4. To determine the heat transfer coefficient, Nusselt no, Thermal resistance and Pressure drop through numerical to predict the thermal performance of a fin for different geometrical configuration.

5. To select best heat sink with suitable fin geometry for lower thermal resistance, higher heat transfer coefficient and with minimum resistance

\subsection{Fin Geometries of Heat Sink}

Geometries of fins in heat sinks are showed in below figure 1

a) Zigzag array.

b) Fluted array.

c) Slanted mirror array.

d) Custom pin fin array.

e) Staggered array. 
These are five different fin geometries are considered for fluid flow and heat transfer analysis.

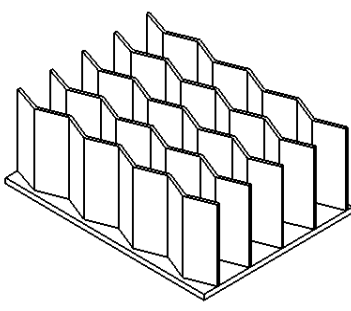

Isometric view Scale: $1: 1$

Fig. a

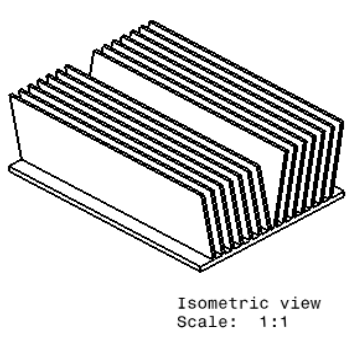

Fig. c

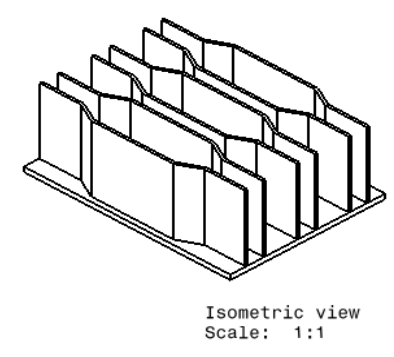

Fig. b

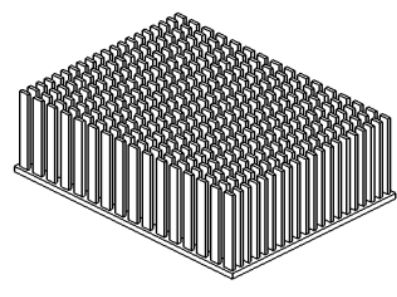

Isometric view
Scale: $1: 1$

Fig. d

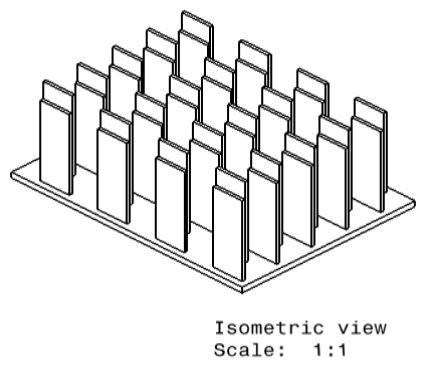

Fig. e

Fig 1 Different Fin Geometries of Heat sinks

\section{LITERATURE REVIEW}

The thermal network of a finned heat sink consists of conductive, radiative, and convective resistances. From the junction of the device, heat is transported by conduction from the device through the interface and into the heat sink from which heat is usually removed by means of convection and radiation cooling to minimize any significant conduction resistance though the fins and improve the overall performance of the heat sink. There exists significant work carried out in the thermal analysis of heat sink design.C.L Chapman et al [1] are analyzed the detailed comparison of thermal performances of different fin geometries by experimentally and theoretically. In this they investigated cross cut pin fin, straight or parallel plate fins and they compare with elliptical pin fins in their work. And they conclude Extruded straight design performed significantly better than either of the other two designs over the flow range examined. Denpange Soodphadkee et al [2] analyzed the performances of Round, Elliptical and Plate fins Staggered and in-line configuration. In this they compare different fin geometries and they were simplifying by assuming periodically developed 2D flow and isothermal heat transfer surface. In general it is found that rounded geometries outperform similarly sharp edged fin shapes. By comparing all finally they concluded staggered shows better performance than in-line. Ambeprasad Kushwal et al [3] are study the comparison of the different shaped finned heat sink by numerical investigation and obtaining the thermal performance as thermal resistance, pressure drop, heat transfer rate, heat transfer coefficient, surface nusselt number. By comparing concluded trapezoidal performs better. Emre Öztürk [4]. He investigated the Heat sink effectiveness, effect of turbulence models, effect of radiation heat transfer and different heat sink geometries were numerically analyzed by commercially available computational fluid dynamics software Fluent for forced cooling. The numerical results are compared with the experimental data. Conjugate heat transfer is simulated for all the electronic cards and packages by solving NavierStokes equations. Qu and Mudawar [5] have performed experimental and numerical investigations of pressure drop and heat transfer characteristics of single-phase laminar flow in $231 \mu \mathrm{m}$ by $713 \mu \mathrm{m}$ channels. De ionized water was employed as the cooling liquid and two heat flux levels, 100 $\mathrm{W} / \mathrm{cm} 2$ and $200 \mathrm{~W} / \mathrm{cm} 2$, defined relative to the planform area of the heat sink, were tested. Good agreement was found between the measurements and numerical predictions, validating the use of conventional Navier-Stokes equations for micro channels. For the channel bottom wall, much higher heat flux and Nusselt number values are encountered near the channel inlet. P.Satyamurty and P.W.Runstadler [6] are evaluated the performances of Planar and Staggered heat sinks with varying heat loads and with varying approach velocities. The comparison is made by computational method, the results obtain that Staggered shows better thermal performance than planar heat sinks. Wang and Peng [7] had investigated experimentally the single-phase forced convective heat transfer characteristics of water/methanol flowing through micro-channels with rectangular cross section of five different combinations, maximum and minimum channel size varying from $(0.6 \times 0.7 \mathrm{~mm} 2)$ to $(0.2$ $\times 0.7 \mathrm{~mm} 2)$. The results provide significant data and considerable insight into the behavior of the forced-flow convection in micro channels.

\section{METHODOLOGY}

Conjugate Heat Transfer analysis is applicable when there are two adjacent regions and one need to analyze the heat transfer between these regions. In case of heat sinks that are attached to active components of electronic devices, convection heat transfer occurs when air is passed over heat fins and conduction heat transfer occurs from base plate (heat source) to the fins. The methodology adopted in this project for conjugate heat transfer analysis consists of the simultaneous calculation of heat conduction in the solid and convective heat transfer in the fluid. The heat is conducted from the base plate to fin and then it is dissipated or taken away from fin to the surroundings through convection process. When air is passed over the fins, heat is dissipated to surroundings and thus it cools the heat fins. 
The first step in the methodology followed is to solve the incompressible Navier Stokes equations with turbulent flow to get the pressure and velocity fields. The flow governing momentum equations (1) with standard $\mathrm{k}-\varepsilon$ turbulence model in indicial notation are given below.

$$
\frac{\partial(\rho k)}{\partial t}+\frac{\partial\left(\rho k u_{i}\right)}{\partial x_{i}}=\frac{\partial}{\partial x_{j}}\left[\begin{array}{c}
\left.\left(\mu+\frac{\mu_{t}}{\sigma_{k}}\right) \frac{\partial k}{\partial x_{j}}\right] \\
S_{k}
\end{array}\right]+P_{k}+P_{b}-\rho \epsilon-Y_{M}+
$$

The next step is to solve the energy equation (2) for both fluid and solid regions to obtain temperature distribution along the length of the fin by applying the interface boundary condition (3) at the coupled region.

$$
\begin{aligned}
& \frac{\partial \mathrm{T}}{\partial \mathrm{t}}+\nabla(\varnothing \mathrm{T})-\nabla(\alpha \nabla \mathrm{T})=0 \\
& \frac{\partial \mathrm{Tsolid}}{\partial \mathrm{t}}-\nabla\left(\alpha_{\text {solid }} \nabla \mathrm{T}\right)=0
\end{aligned}
$$

Above equations are partial differential equations that cannot be solved by analytically and hence one has to use numerical techniques like finite difference method, finite volume method to get the required solutions. Computer simulation procedure is followed to get the required solutions within the reasonably accepted values. For this purpose computer simulations can be carried out using commercially available FLUENT® software.

\subsection{Governing Equations in CFD}

There are mainly three equations that we solve in computational fluid dynamics problems. They are continuity equation, momentum equation and energy equation. These three equations are collectively called Navier Stokes equations. The flow of most fluids may be analyzed by mathematically solving the last two equations. These three equations represent the conservation of mass, momentum and energy respectively. These three equations are represented as below.

\section{Continuity Equation}

$$
\frac{\partial u}{\partial x}+\frac{\partial v}{\partial y}+\frac{\partial w}{\partial z}=0
$$

\section{Momentum (Navier Stokes) Equations}

\section{X-Momentum Equation}

$$
\begin{aligned}
& \rho\left(u \frac{\partial u}{\partial x}+v \frac{\partial u}{\partial y}+w \frac{\partial u}{\partial z}\right) \\
& =-\frac{\partial \rho}{\partial x} \\
& +\mu\left(\frac{\partial^{2} u}{\partial x^{2}}+\frac{\partial^{2} u}{\partial y^{2}}+\frac{\partial^{2} u}{\partial z^{2}}\right)
\end{aligned}
$$

\section{Y-Momentum Equation}

$$
\begin{aligned}
& \rho\left(u \frac{\partial v}{\partial x}+v \frac{\partial v}{\partial y}+w \frac{\partial v}{\partial z}\right) \\
& =-\frac{\partial \rho}{\partial y} \\
& +\mu\left(\frac{\partial^{2} v}{\partial x^{2}}+\frac{\partial^{2} v}{\partial y^{2}}+\frac{\partial^{2} v}{\partial z^{2}}\right)
\end{aligned}
$$

\section{Z-Momentum Equation}

$$
\begin{aligned}
& \rho\left(u \frac{\partial w}{\partial x}+v \frac{\partial w}{\partial y}+w \frac{\partial w}{\partial z}\right) \\
& =-\frac{\partial \rho}{\partial z} \\
& +\mu\left(\frac{\partial^{2} w}{\partial x^{2}}+\frac{\partial^{2} w}{\partial y^{2}}+\frac{\partial^{2} w}{\partial z^{2}}\right)
\end{aligned}
$$

\section{Energy Equation}

$$
\begin{aligned}
& \left(\mathrm{u} \frac{\partial \mathrm{T}}{\partial \mathrm{x}}+\mathrm{v} \frac{\partial \mathrm{T}}{\partial \mathrm{y}}+\mathrm{w} \frac{\partial \mathrm{T}}{\partial \mathrm{z}}\right) \\
& =\frac{1}{\alpha}\left(\frac{\partial^{2} \mathrm{~T}}{\partial \mathrm{x}^{2}}+\frac{\partial^{2} \mathrm{~T}}{\partial \mathrm{y}^{2}}\right. \\
& \left.+\frac{\partial^{2} \mathrm{~T}}{\partial \mathrm{z}^{2}}\right)
\end{aligned}
$$

\subsection{Problem Solving in Ansys Fluent}

In this, there are mainly 3 steps for solving the problem in hand.

1. Pre-processing.

2. Solver.

3. Post processing.

In pre- processing made the heat sink model in CATIA V5 R20.These files imported to FLUENT 14.5 workbench. In Ansys work bench selecting the unit in millimeter. Making a fluid body and rename to the base plate walls fins are subtracts in the solid body from fluid body and gave the name as inlet, outlet and walls.

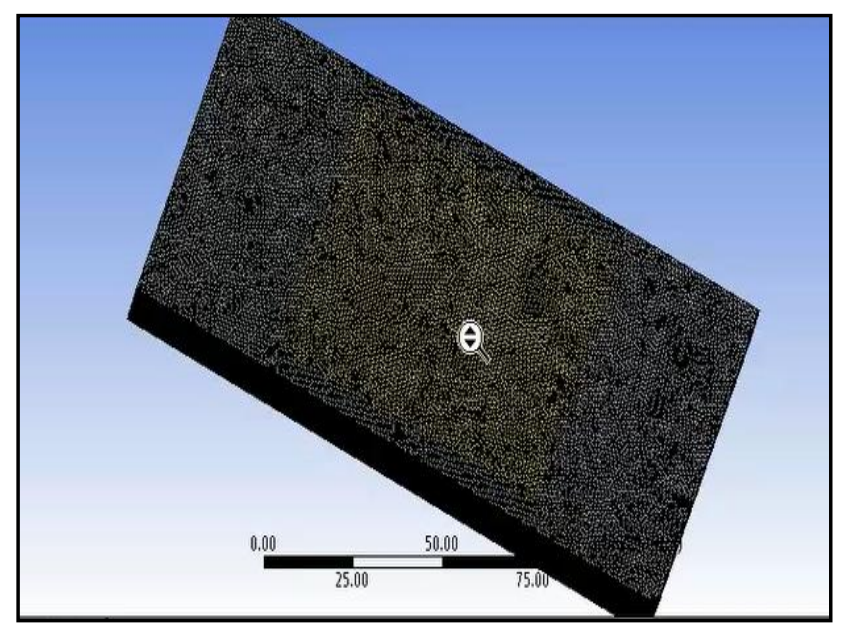

Fig 2 Mesh generation 
In mesh generation element size $1 \mathrm{~mm}$ and checking the skewness factor. In solver, Gauss siedel solution method is used and solution control is retain the default and give the solution initialization and running the hybrid run and running the calculation. In the post processing process visualize clearly through and we can analyze by range of color coding like velocity vector, pressure contours and temperature contours etc.

\section{RESULTS AND DISCUSSION}

The conjugate heat transfer analysis of fins is carried out by using commercial available FLUENT® software and turbulence module is used to account for turbulence phenomenon. Standard $\mathrm{k}-\varepsilon$ model is used for turbulence model.

Conjugate heat transfer simulation work consists of analysis of both convection heat transfer and conduction heat transfer processes. The air (fluid) flows over the fins at the interface regions of both solid and fluid. The main equations are solved for fluid flows are the momentum equations and turbulence-modeling equations. Solution of these Navier-
Stokes equations gives the velocity vectors and pressures in the fluid flow region. FLUENT® has capability to solve Navier-Stokes equations with standard k- $\varepsilon$ applied turbulence model.

The energy equation is solved for both fluid (convection heat transfer) and solid (conduction heat transfer) regions to obtain temperature distribution along the length of the fin by applying the interface boundary conditions at the coupled region.

As the first step of the present study, the CFD results have to be validated against analytical values or experimental values or previous literature data.

The overview of the results of present study involves CFD validation and parametric study conducted for different configuration of fins at a constant velocity $3.933 \mathrm{~m} / \mathrm{s}$ in a duct. And made comparison with zig zag, fluted, slanted mirror, custom pin fin and staggered fin configuration models.

Table1. Variation of Thermal Performance of Heat Sink

\begin{tabular}{|c|c|c|c|c|c|c|}
\hline Fin profile & $\begin{array}{l}\text { Heat } \\
\text { Load } \\
(W)\end{array}$ & $\begin{array}{l}\text { Surface heat } \\
\text { transfer } \\
\text { coefficient } \\
\left(\mathrm{W} / \mathbf{m}^{2} \mathbf{k}\right)\end{array}$ & $\begin{array}{l}\text { Max. } \\
\text { Temp } \\
(k)\end{array}$ & $\begin{array}{l}\text { Thermal } \\
\text { Resistance } \\
(\mathrm{K} / \mathbf{w})\end{array}$ & $\begin{array}{l}\text { Total } \\
\text { Pressure } \\
\text { Drop } \\
\text { (pa) }\end{array}$ & $\begin{array}{l}\text { Surface } \\
\text { Nusselt No }\end{array}$ \\
\hline & 50 & 154.44 & 338.2 & 0.8000 & 19.75 & 6380 \\
\hline \multirow[t]{3}{*}{ Zigzag Array } & 75 & 166.77 & 358.6 & 0.8080 & 19.88 & 6889 \\
\hline & 100 & 173.52 & 379.3 & 0.8130 & 26.40 & 7170 \\
\hline & 50 & 153.76 & 332.1 & 0.6820 & 21.34 & 6350 \\
\hline \multirow[t]{3}{*}{ Fluted Array } & 75 & 167.21 & 349.2 & 0.6826 & 21.49 & 6910 \\
\hline & 100 & 174.55 & 366.5 & 0.6851 & 28.84 & 7212 \\
\hline & 50 & 215.55 & 316.4 & 0.3680 & 21.34 & 8913 \\
\hline $\begin{array}{l}\text { Slanted } \\
\text { Mirror }\end{array}$ & 75 & 215.21 & 325.6 & 0.3681 & 21.33 & 8891 \\
\hline \multirow[t]{2}{*}{ Array } & 100 & 215.72 & 334.9 & 0.3690 & 23.28 & 8906 \\
\hline & 50 & 130.54 & 313.5 & 0.3100 & 119.04 & 5393 \\
\hline \multirow{3}{*}{$\begin{array}{ll}\text { Custom Pin } \\
\text { Fins }\end{array}$} & 75 & 156.61 & 321.2 & 0.3093 & 119.81 & 6470 \\
\hline & 100 & 175.25 & 329.0 & 0.3100 & 119.873 & 7239 \\
\hline & 50 & 129.63 & 329.4 & 0.6280 & 22.19 & 5949 \\
\hline \multirow{2}{*}{$\begin{array}{l}\text { Staggered } \\
\text { Array }\end{array}$} & 75 & 144.01 & 345.2 & 0.6293 & 22.46 & 6299 \\
\hline & 100 & 152.41 & 361.1 & 0.6310 & 22.68 & 5357 \\
\hline
\end{tabular}

From the table 1 it is observed that slanted mirror fin array gives the almost constant heat transfer a coefficient value that is highest among all other fin configurations. Thermal resistance is minimum for custom pin fins but gives higher pressure drop. In the other hand zigzag fin configuration gives lowest pressure drop. Slanted mirror array is decided as best fin configuration which gave consistent higher heat transfer coefficient with reasonable low pressure drop.
Slanted mirror array geometry temperature, pressure and velociy contour for $50 \mathrm{~W}$ 


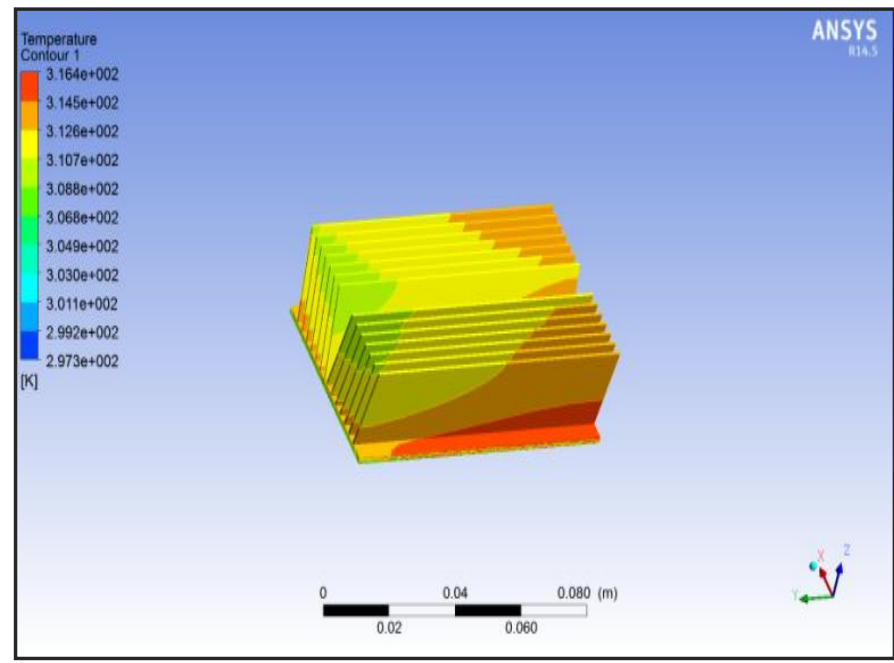

Fig .3 Temperature contour

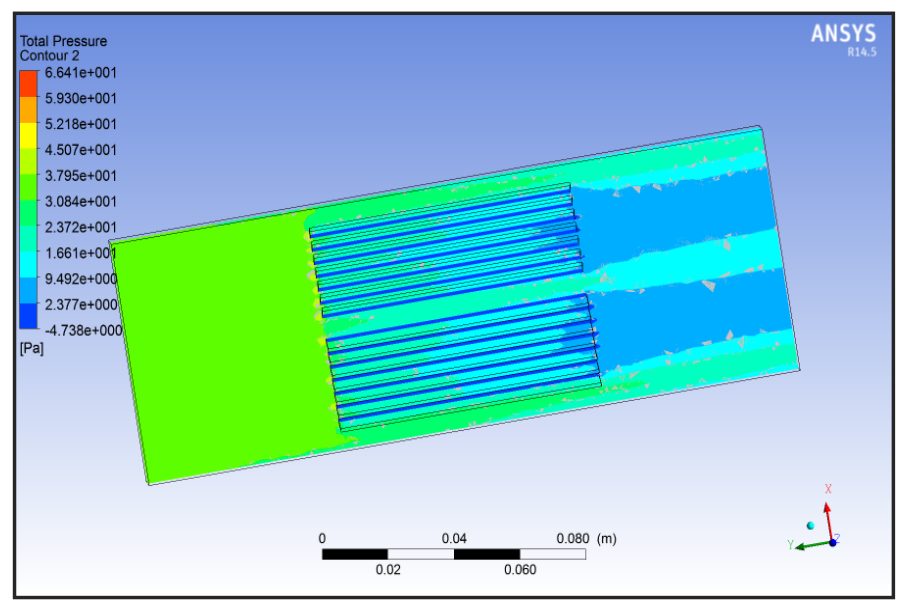

Fig .4 Pressure contour

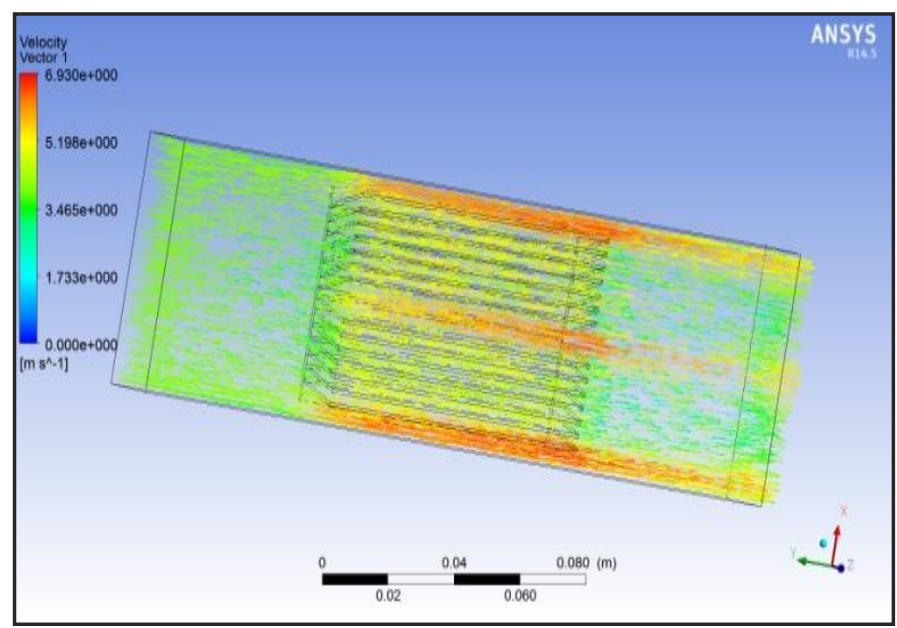

Fig .5 Velocity contour

\section{CONCLUSION}

In this Project work, numerical analysis of different fin geometries of heat sinks for forced convection heat transfer and their comparison carried out by using CFD technique. Five different fin geometries were created and effect of heat load on thermal performances are studied and presented through graphs and contours.
For all five fin geometries compared for the maximum temperature attained on the basis of result governed by the CFD and conjugative heat transfer analysis. With fin space $2.8 \mathrm{~mm}$ Slanted mirror array geometry of heat sink model shows that lowest maximum temperature attained compared to Zigzag, Fluted and Staggered array geometry of heat sink. Zigzag shows maximum temperature attained, which is not desirable and Custom pin fin model shows lowest maximum temperature attained with high pressure drop, which is not desirable. Surface heat transfer coefficient and surface Nusselt number is maximum in Slanted mirror array heat sink with different heat loads of $50 \mathrm{~W}, 75 \mathrm{~W}$ and $100 \mathrm{~W}$.

As per criterion for selection of heat sink, the heat sink should have lowest Thermal resistance, low pressure drop and maximum surface heat transfer coefficient.

The Slanted mirror array heat sink shows the lowest thermal resistance and maximum surface heat transfer coefficient with low pressure drop. It has the lowest maximum temperature attained compared to other fin geometry heat sink models and with best surface nusselt number for a given heat load of $50 \mathrm{~W}, 75 \mathrm{~W}$ and $100 \mathrm{~W}$.

Slanted Mirror Array fin geometry heat sink shows the best thermal performances and fulfills criteria for selection of heat sink compared to other geometries of heat sink models and it is manufacturable and producible

\section{ACKNOWLEDGEMENTS}

My heart full thanks to our beloved HOD and my Guide Dr.V.M.Kulkarni who patronized and encouraged me in carrying out this Dissertation work successfully.

\section{REFERENCES}

[1] C. L. Chapman, S. Lee, and B. L. Schmidt, "Thermal Performance of an Elliptical Pin Fin Heat sink," Proceedings of the Tenth IEEE Semiconductor Thermal Measurement and Management Symposium (Semi-Therm), San José, California, February 1-3, pp. 24-31, 1994.

[2] Denpong Soodpadhkee, Masud Behnia and Watabe, 'A comparison of heat sinks in Laminar forced convection: part I- Round, Elliptical, and Plate Fins Staggered and Inline configuration'. IJMP - Volume 24 NO-1, in 2001.

[3] Ambeprasad Kushwaha and Prof. Ravindra Kirar, 'Comparative study of Rectangular, Trepezoidal and Parabolic shaped Finned Heat sink'. IOSR - 22781684 Volume 5 Issue 6 - Apr 2013.

[4] Ozturk' E (2004). CFD Analysis of heat sinks for CPU cooling with FLUENT. M.S thesis, Middle East Technical University, Ankara, Turkey.

[5] Qu, W. and Mudawar, I. 2002. Experimental and numerical study of pressure drop and heat transfer in a single-phase micro-channel heat sink. International Journal of Heat and Mass Transfer. 45, 2549 - 2565. 
[6] P. Sathyamurthy, P.W. Runstadler, and S. Lee, "Numerical and Experimental Evaluation of Planar and Staggered Heat Sinks," Proceedings of the Fifth InterSociety Conference on Thermal Phenomena in Electronic Packaging (Itherm), Orlando, Florida, May 28 - June 1, pp. 132-139, 1996.

[7] Peng, X. F., Wang, B. X., Peterson, G. P., and Ma, H. B. 1995. Experimental investigation of heat transfer in flat plates with rectangular micro channels. International Journal of Heat and Mass Transfer. 38,127-137. 